\title{
Liturgia y espacio urbano en Barcelona
}

\author{
Liturgy and Urban Space in Barcelona
}

Magda Mària i Serrano y Alba Arboix-Alió · Universitat Politècnica de Catalunya (España)

https://doi.org/10.17979/aarc.2013.3.0.5095

\section{RESUMEN}

El edificio sacro tiene un área de influencia que va más allá de la parcela que ocupa. Esta comunicación reflexiona sobre la capacidad de los espacios urbanos —especialmente los contiguos a los templos- de cambiar sus atribuciones de paso y convertirse, con pocos medios, en plataformas de socialización o en una extensión de las funciones litúrgicas. Ejemplos de calles y plazas utilizadas como habitaciones comunitarias se enlazan con episodios pasados y presentes de la historia religiosa de Barcelona, ilustrando cómo soluciones imaginativas, unidas a una buena gestión, pueden llegar a transformar las vías públicas en espacios sociales entre los edificios para acoger ceremonias multitudinarias, sin necesidad de construir costosas infraestructuras. Una manera de operar más acorde con la austeridad presente en los evangelios.

\section{ABSTRACT}

The influence area of a temple is greater than the plot where it is built. The aim of this article is to think about the potential of urban spaces — particularly the ones attached to churches. They can turn their crossing point attributes into liturgical and socialisation ones. Some historical and contemporary examples of urban areas in Barcelona used like community room are given. All of them show that only with a good management and with few reversible elements is possible to transform the common urban space into living space between buildings. With this attitude is not even necessary to build any costly disposable infrastructure to shelter any kind of major event. And it is a way of act more in accordance with the austerity of the Gospels.

\section{PALABRAS CLAVE}

Espacio urbano; efemérides; reutilizar; Barcelona; liturgia urbana.

\section{KEYWORDS}

Urban Space; Major Events; Reuse; Barcelona; Urban Liturgy. 


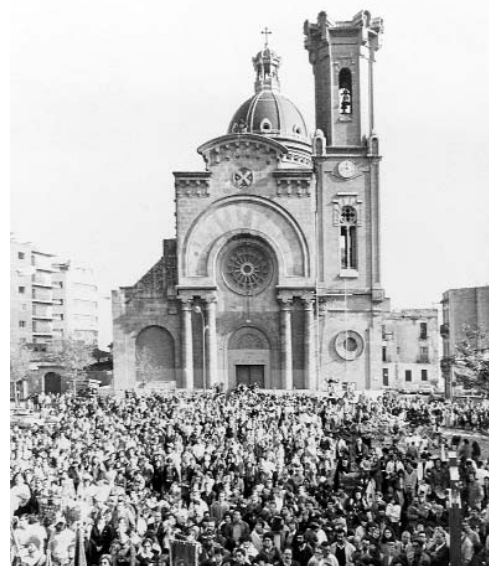

Fig. 01. Pere Falqués i Urpí, Sant Andreu del Palomar, Barcelona, 1850.

\section{MÁS ALLÁ DEL EDIFICIO SACRO}

El edificio sacro tiene un área de influencia que va más allá de la parcela que ocupa. En realidad, el interior de la ecclesia no deja de ser una gran plaza pública cubierta, un lugar de reunión y encuentro. Esta vida comunitaria se extiende al exterior, y el espacio urbano adyacente se convierte en una estancia a cielo abierto que acompaña al templo. Una reserva de suelo que resulta imprescindible en los momentos de entrada o salida de las ceremonias pero que, a la vez, también se convierte en lugar de referencia y uso urbano para el resto de los ciudadanos (Fig. 01).

Las dimensiones y cualidades de los espacios exteriores adyacentes a los templos son requerimientos que Rafael Moneo consideró imprescindibles en el diseño de la nueva catedral de Los Ángeles, California, construida entre 1998 y 2002. Además de la superficie de la propia catedral, de $4.000 \mathrm{~m}^{2}$, el conjunto incluye una amplia plaza destinada a congregaciones multitudinarias que ocupa el centro de la parcela. Una gran cruz recortada sobre el muro del ábside conforma, interiormente, el lucernario de alabastro que baña de luz el presbiterio. Exteriormente, esa misma cruz actúa de telón de fondo de la plaza, convirtiéndola en una gran nave al aire libre (Fig. 02).

En Barcelona, la existencia de grandes espacios vacíos en los alrededores de las iglesias contribuye a

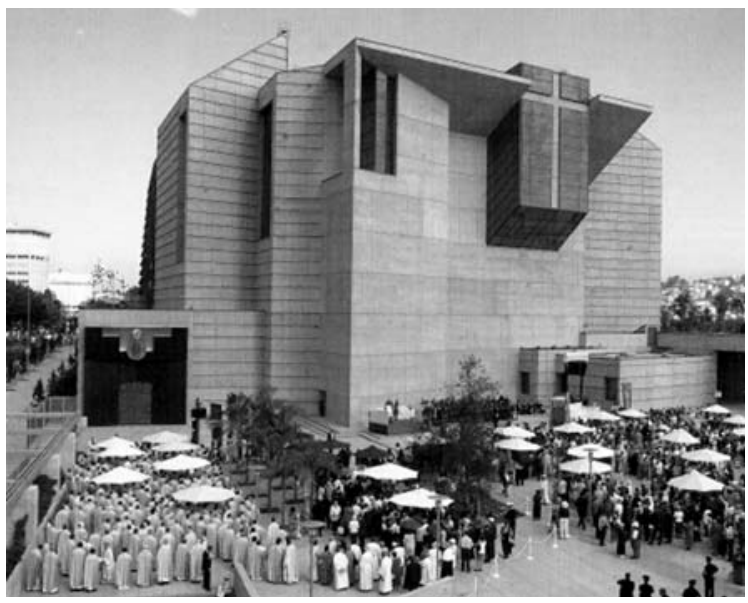

Fig. 02. Rafael Moneo Vallés, Catedral de Nuestra Señora de los Angeles, Los Ángeles (EEUU), 1996-2002.

dotar de mayor versatilidad a los templos, no sólo a los de nueva planta sino también a los ya existentes ${ }^{1}$. Un buen ejemplo nos lo brinda la parroquia de la Mare de Déu de la Mercè. La actual iglesia se inicia en 1765, pero en 1982 se derriba toda una manzana para abrir una plaza y así dotar a esta parroquia de mayor luz, salubridad y extensibilidad.

La influencia de un templo en el espacio urbano es tan intensa que su radio de acción empieza por determinar el nombre del lugar. Muchas calles o plazas llevan el nombre del templo que les ofrece su fachada principal, su lateral o su ábside ${ }^{2}$, siendo una demostración palpable de cómo la importancia de una iglesia se vuelca hacia el espacio urbano.

\section{LA CALLE COMO ESTANCIA COMUNITARIA}

Sin embargo, muchas calles y plazas adyacentes a las iglesias sólo sirven para circular y no para quedarse en ellas, siendo utilizadas más como infraestructuras para el automóvil que como espacios habitables al aire libre $^{3}$. Para mejorar esta situación, el espacio público que se encuentra junto a los templos ha de poder convertirse en un lugar que tenga las características necesarias para albergar usos diversos que complementen las funciones religiosas y que, a la vez, ofrezcan un ámbito de calidad a los ciudadanos (Fig. 03). De hecho, Ildefons Cerdà, cuando diseñó el ensanche de 

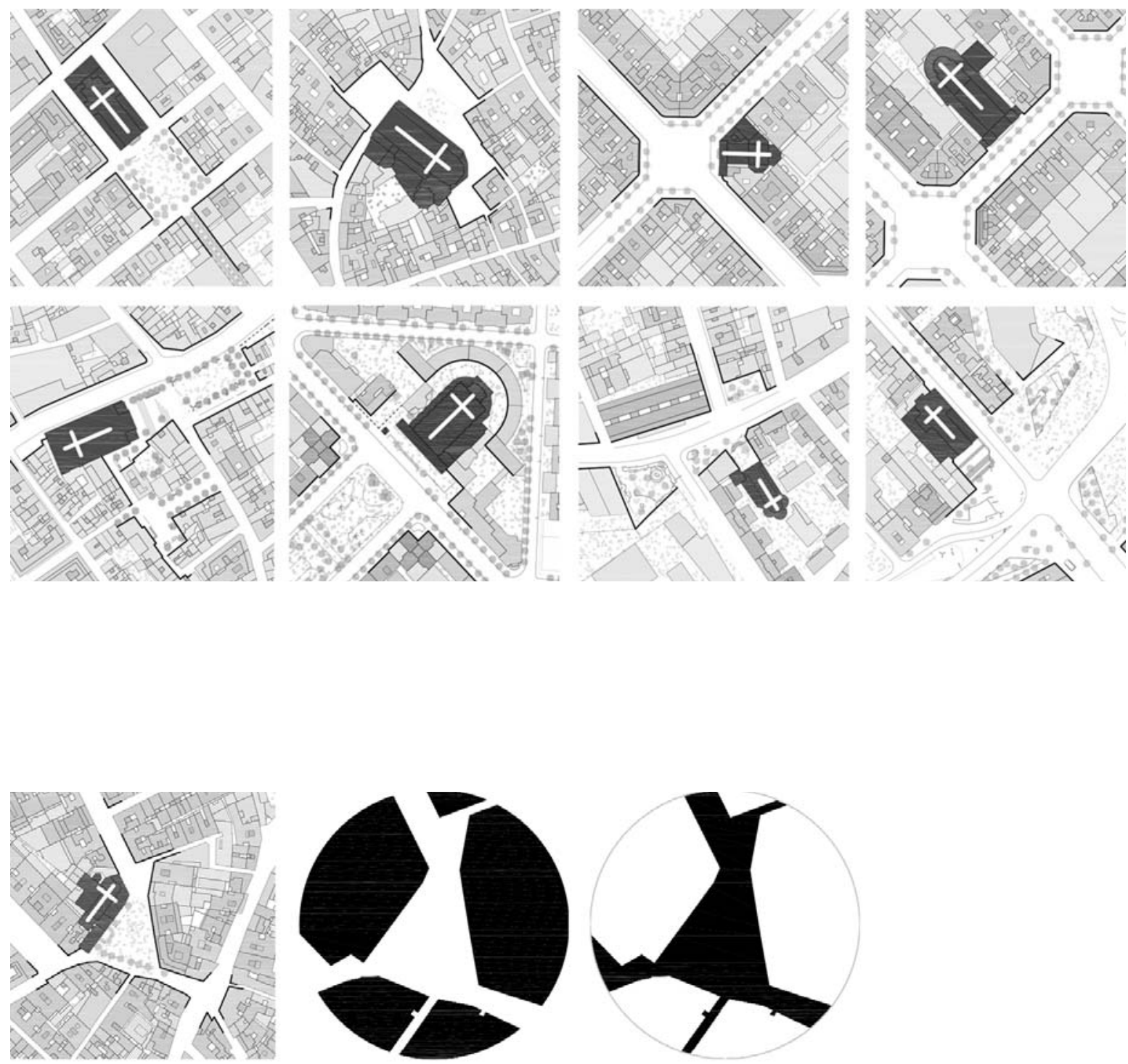

Fig. 03. Dibujo de ocho parroquias en distintos enclaves urbanos de Barcelona (2013). Hay situaciones en las que el espacio urbano adyacente al templo puede ser usado como habitación a cielo abierto donde extender sus funciones litúrgicas; en otras, en cambio, la calle sólo puede ser utilizada como infraestructura de paso. Aparecen dibujadas la siguientes iglesias parroquiales: Sant Joan de Gràcia, Santa Maria del Pi, Mare de Déu dels Angels, Sant Josep Oriol, Sant Vicenç, Sant Medir, Sant Pius X y Verge de Gràcia i Sant Josep.

Fig. 04. Dibujo del espacio exterior en negativo y en positivo de la plaza de Sant Pere de les Puel-les, Barcelona, 2013. 

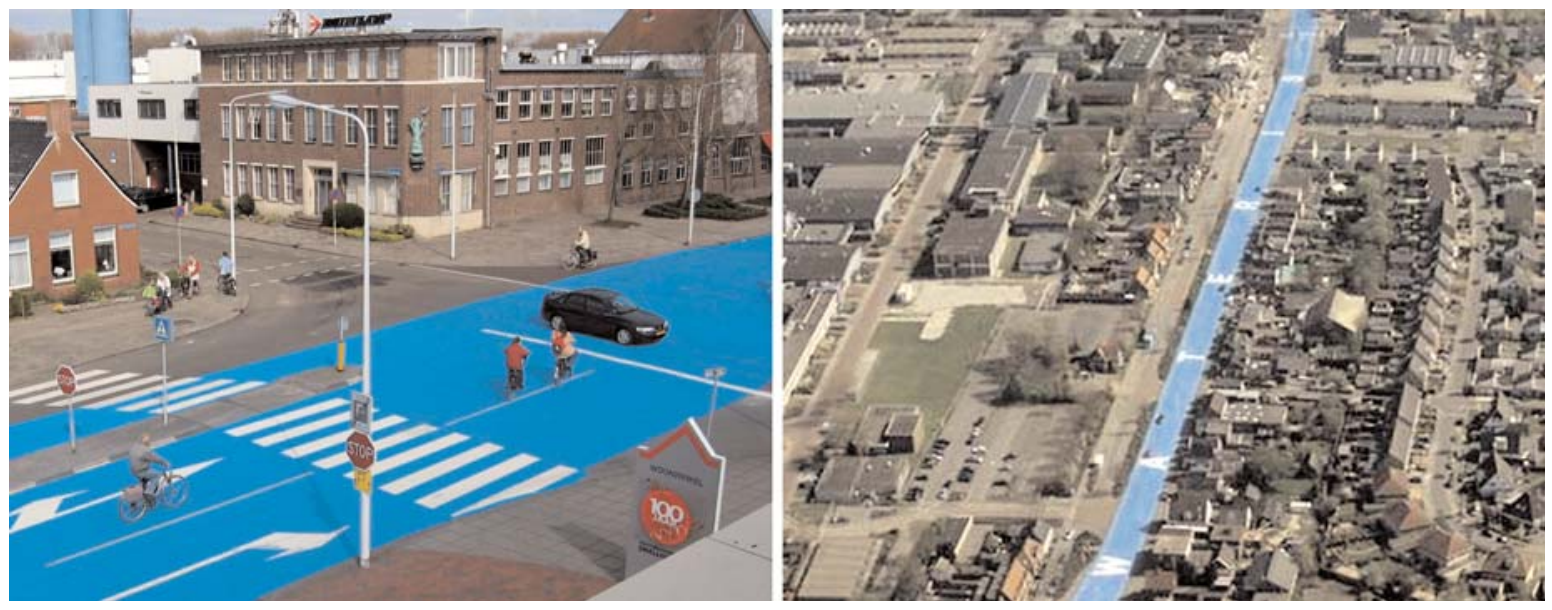

Fig. 05. Henk Hofstra, Water is Leven. Acción artística en Drachten (Países Bajos), 2007.

Barcelona, ya se refería a la calle como espacio público. El polifacético ingeniero diferenciaba vía de calle, siendo para él ésta última «el patio anterior de la casa»"

Louis I. Kahn se refiere al espacio público como lugar de encuentro y convivencia, y a la necesidad de que la calle funcione como recinto al aire libre: «La calle es una estancia que expresa un pacto (...) La calle es una estancia comunitaria» ${ }^{5}$. Por su parte, Christopher Alexander explica que los espacios al aire libre, lejos de ser considerados como lugares vacíos entre edificios, han de leerse como espacios positivos ${ }^{6}$. Así, edificios y espacio entre edificios deben entenderse indistintamente como fondo y figura, por tener ambos una forma determinada (Fig. 04).

Para hacer más versátil el funcionamiento de calles y plazas, la supresión de elementos distorsionadores que atenúe una concreta especialización de usos resulta particularmente importante. Arquitectos como Camillo Sitte y Aldo van Eyck alaban las condiciones de las calles cuando están nevadas, precisamente porque la nieve hace desaparecer desniveles y zonificaciones, y permite una mayor libertad de movimiento y alteridad de usos?. Y lo mismo pasa con los adoquinados de muchas plazas y calles europeas, donde coches y tranvías circulan al mismo nivel que los peatones. Esta situación permite organizar cualquier actividad sin el impedimento de las divisiones especializadas. Recientemente, diversas acciones artísticas han incidido en este tema, demostrando cómo el cambio de color de la calzada invita a ver y a utilizar la calle de otra manera. Un ejemplo paradigmático es el de La calle azul. En 2007, el artista Henk Hofstra pintó una avenida de Drachten (Países Bajos) de color azul eléctrico. Con este mecanismo tan económico de uniformizar y personalizar el espacio público, brindó la posibilidad a los ciudadanos de reinterpretar la calle, pudiendo situar en un marco diferente y más doméstico sus actividades cotidianas ${ }^{8}$ (Fig. 05).

\section{LA CALLE COMO EFEMÉRIDES}

El arquitecto Bernard Rudofsky considera que las naciones históricamente discriminadas por su pobreza utilizan de manera excelente las calles de sus ciudades. Precisamente son vividas como volúmenes de tres dimensiones, inseparables de su medio ambiente, y no sólo percibidas como áreas bidimensionales ${ }^{9}$. En estos países - entre los que se encuentra España-, la calle es el gran teatro del mundo: lugar de funerales, festividades, procesiones o plegarias públicas; lugar de gran variedad de eventos. Y esto es algo que está latente en toda su cultura a lo largo de siglos de historia ${ }^{10}$.

La habilitación del espacio público para ceremonias de distinto tipo se acentúa más durante el barroco, y la arquitectura de las ciudades se utiliza como soporte escenográfico para demostrar el poder político y reli- 

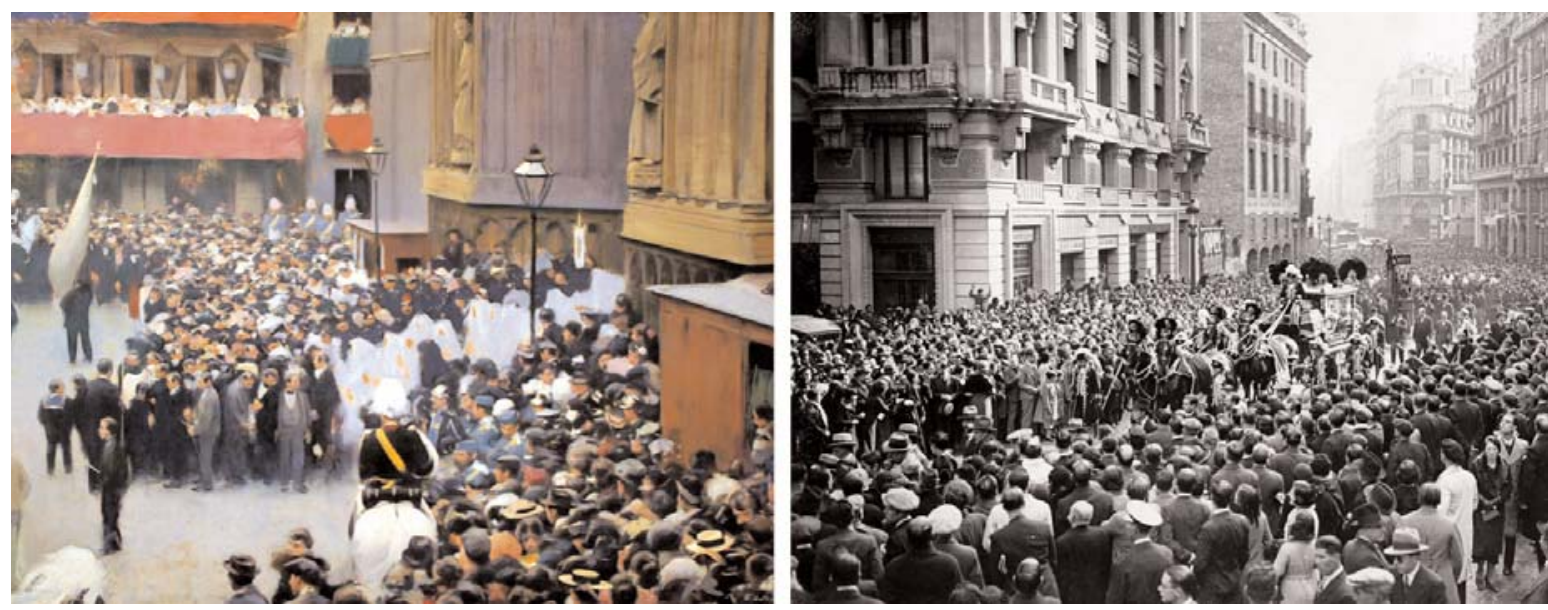

Fig. 06. Comparación de una pintura y una fotografía de dos ceremonias en las calles de Barcelona. Izq: Ramón Casas, Procesión del Corpus Chisti en la iglesia de Santa Maria del Mar, Barcelona, 1907. Der: Carroza fúnebre de Amadeu Vives pasando por la Via Laietana, Barcelona, 1932.

gioso $^{11}$. En Barcelona fueron frecuentes las ceremonias frente a las puertas de las murallas romana y medieval ${ }^{12}$. Grabados y pinturas de época representan procesiones, bendiciones o celebraciones eucarísticas en algunas calles y plazas emblemáticas de la ciudad. Más adelante, la fotografía nos ofrece imágenes de avenidas abarrotadas de ciudadanos que participan en ceremonias religiosas, festivas o funerarias (Fig. 06). Una demostración más de la versatilidad de la calle para acoger acontecimientos diversos. Porque, tal como afirma Rudofsky, «en la calle está la acción» ${ }^{13}$.

Alison y Peter Smithson definen tres características de la calle que van unidas a las necesidades asociativas de los ciudadanos: la permanencia, la periodicidad y la efemérides ${ }^{14}$. Las dos primeras deben producirse de manera habitual para mejorar la vida cotidiana de la sociedad. La tercera se produce aisladamente, de manera estratégica, para acoger un acontecimiento extraordinario. En este sentido, las posibilidades que ofrecen los espacios urbanos para acoger importantes efemérides son múltiples, demostrando así su versatilidad. Ceremonias multitudinarias pueden llevarse a cabo en diversos enclaves de una ciudad de manera simultánea, con los recursos disponibles, sin la obligación de construir ex profeso equipamientos o infraestructuras de nueva planta.

En Barcelona se recuerdan varias efemérides religiosas encadenadas durante el pontificado del activo arzobispo Gregorio Modrego (1942/67), que pusieron a prueba la capacidad de la ciudad para aprovechar edificios existentes y espacios libres, por un lado, o impulsar nuevas infraestructuras, por otro $^{15}$. Durante el XXXV Congreso Eucarístico Internacional de 1952 se alternaron las dos estrategias. Se utilizaron plazas, calles y avenidas para celebraciones, reuniones, cónclaves, conciertos, exposiciones y representaciones, pero también construcciones ya existentes. En la plaza de la Catedral, en el paseo de San Juan o en la avenida María Cristina se congregaron miles de ciudadanos. Pero también la sala Oval del Palacio Nacional de Montjuïc, el estadio Olímpico, el Palacio de la Música o el Paraninfo de la Universidad, acogieron múltiples actos.

Por otro lado, el Congreso Eucarístico impulsó la urbanización de un amplio sector de la ciudad -el barrio del Congrés-, promocionando viviendas y equipamientos. También se construyeron ex profeso importantes escenografías para algunas celebraciones, similares a las grandes estructuras efímeras del Barroco. En el estadio de Montjuïc se alzaron sobre el césped veintiún altares; en la avenida Diagonal se erigió un monumental altar, desmontado después de la clausura; y la avenida María Cristina, la plaza de la Catedral e innumerables puntos de la ciudad se decoraron efímera y costosamente para la ocasión (Fig. 07) ${ }^{16}$. Visto desde la actualidad, la pregunta es inevitable: 

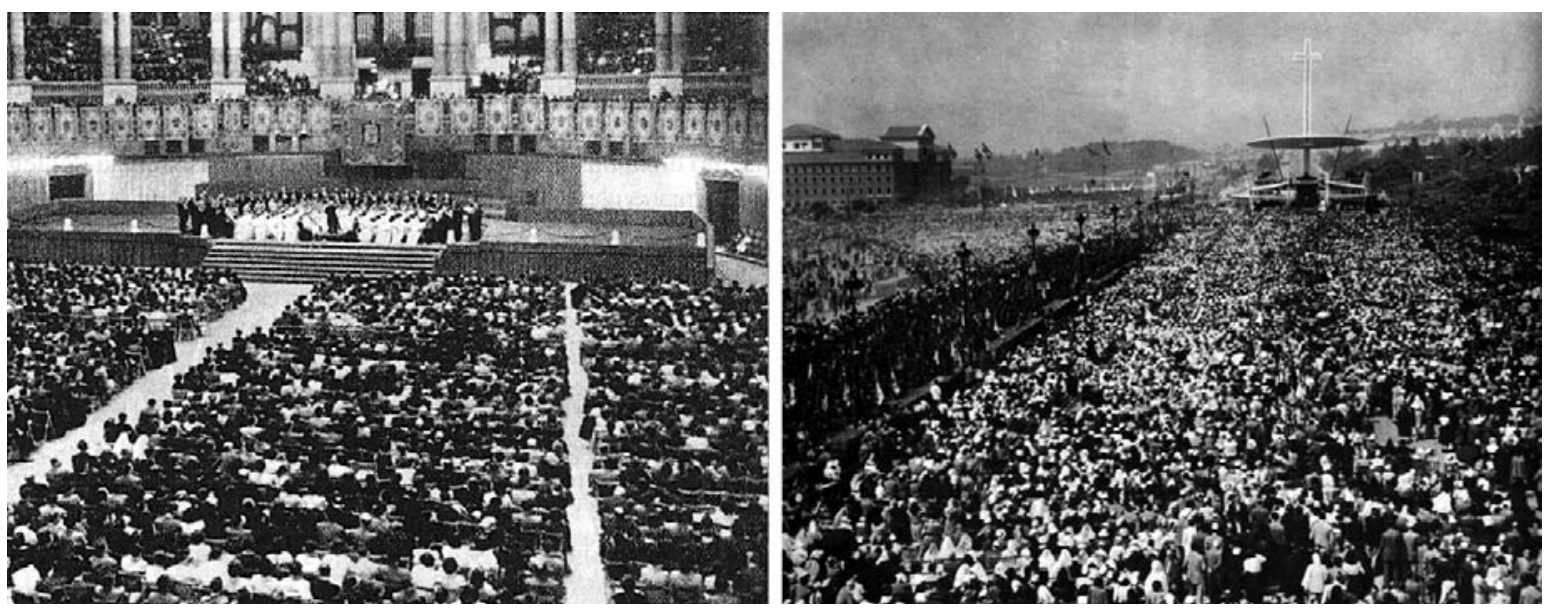

Fig. 07. Comparación de dos actos del XXXV Congreso Eucarístico Internacional de Barcelona de 1952. En el primero se aprovecha un edificio existente; en el segundo, se construye ex profeso toda la escenografía. Izq: Interior de la Sala Oval del Palacio Nacional de Montjuïc. Der: Altar monumental erigido en la actual plaza de Pío XII de la avenida Diagonal, desmontado después de la clausura.

¿hacía falta este dispendio público para unas infraestructuras efímeras que no volverían a ser reutilizadas?

Este aprovechamiento de un evento civil o religioso extraordinario para urbanizar sectores degradados de la ciudad es comprensible en los años del desarrollismo, y forma parte también de la historia de Barcelona ${ }^{17}$. Pero también se produjo con la excusa de acontecimientos deportivos como los Juegos Olímpicos de 1992 o culturales, como el Fòrum de les Cultures de 2004.

La estrategia contraria, la del reciclaje, es la que se llevó a cabo en Londres durante los Juegos Olímpicos del año 2012. En lo que atañe a las infraestructuras deportivas, los londinenses apostaron por sacar partido de sus edificaciones, construyendo ex novo sólo aquellas que tenían una baja capacidad de aforo para conseguir su reutilización posterior ${ }^{18}$. Richard Sennett habla de la reparación dinámica como manera de completar y corregir lo existente para alargar su vida con un nuevo uso $^{19}$. Esta estrategia, aplicada al parque edificado y al espacio urbano, permite completarlo y adaptarlo a nuevas funciones, y representa un excelente ejemplo de cambio de actitud muy acorde con la actual situación de crisis económica.

\section{MISAS EN LA CALLE}

Algunas de las ceremonias religiosas de antaño vinculadas al espacio público se siguen llevando a cabo periódicamente en nuestro país: bendiciones, procesiones y fiestas patronales forman parte del imaginario colectivo y de la cultura popular mediterránea (Fig. 08).

En el otro extremo de esta utilización ceremonial pero a la vez teatral y lúdica - de las manifestaciones religiosas en la calle, estaría la vertiente reivindicativa o de extrema necesidad. Por un lado, noticias provenientes de América Latina nos muestran la celebración de misas en la calle para llamar la atención de los políticos. Se utiliza el espacio exterior adyacente a los templos para demandar, a través de la celebración eucarística, una situación injusta ${ }^{20}$. Por otro lado, el traslado de la celebración religiosa a la calle puede responder a una situación de extrema necesidad. En el año 2010, un terremoto afectó seriamente los templos de Chile, y la alternativa para que la vida litúrgica no se viera interrumpida fueron las plazas públicas. Muchas de estas ceremonias aprovecharon un lateral o la propia fachada principal del templo como telón de fondo. Y en Barcelona, durante los años posteriores a la Guerra Civil o en situaciones de provisionalidad, se utilizaron estructuras ligeras de lona para convertir los espacios exteriores a los templos en iglesias de emergencia (Fig. 09). El resultado de estas traslaciones eucarísticas a la calle es lo más parecido a lo que Kahn denominaba «la calle como estancia comunitaria».

Más allá de una situación reivindicativa o de emergencia, un ejemplo reciente de practicidad en la ocupa- 

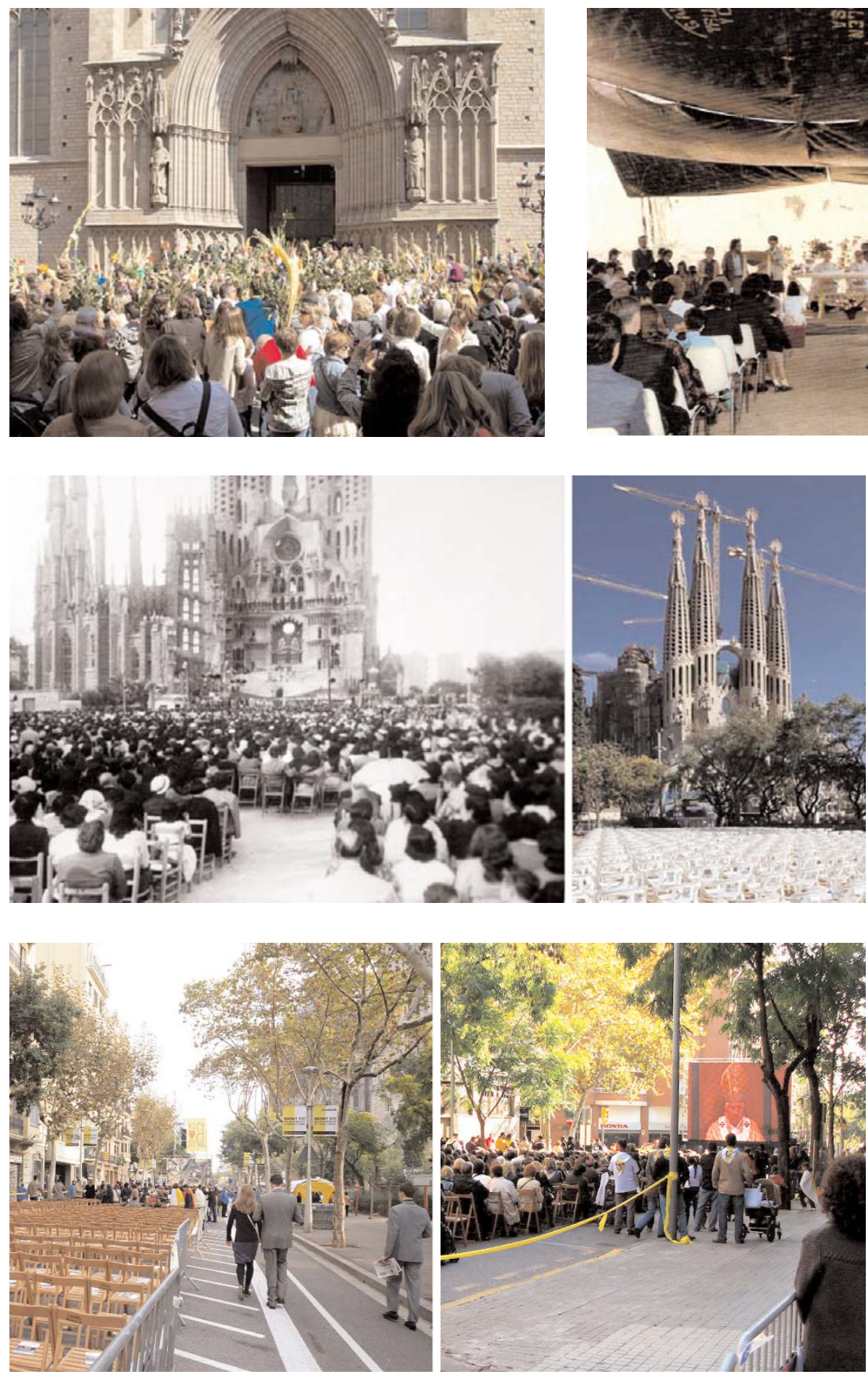

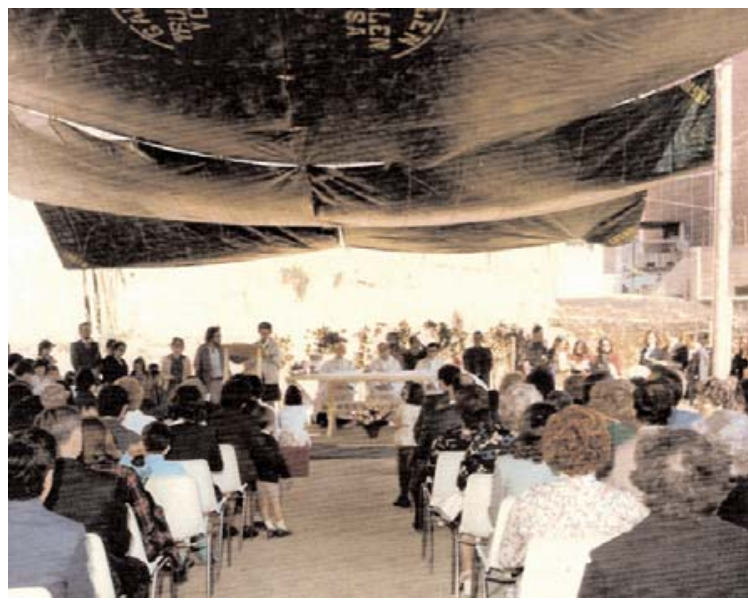

Fig. 08. Domingo de Ramos en Santa Maria del Mar,

Barcelona, 2012. Una demostración de que la plaza sigue realizando las mismas funciones religiosas que aparecen en el cuadro de Ramón Casas de 1907.

Fig. 09. Parroquia de Sant Marcel, Barcelona (1979). Comunión de veinte niños y niñas. Mientras se realizan obras en la iglesia, la liturgia se celebra al aire libre, en el patio de manzana.

Fig. 10. Comparación de dos celebraciones religiosas separadas 68 años con el mismo telón de fondo: la Sagrada Familia. Izq: Sillas de madera dispuestas en la plaza contigua a la basílica para celebrar una misa al aire libre durante el

Congreso Eucarístico de 1952. Der: Sillas de plástico dispuestas en la plaza con-

tigua a la basílica para seguir desde el exterior y mediante pantallas la misa oficiada por el papa Benedicto XVI en el interior del templo.

Fig. 11. Vista de la misma calle, antes y durante el seguimiento mediante pantallas del acto de dedicación del templo expiatorio de la Sagrada Familia

(2010). 
ción del espacio público para organizar una efemérides religiosa lo encontramos de nuevo en Barcelona. En noviembre de 2010, la ciudad estableció una estrategia de aprovechamiento de calles y plazas durante la visita del papa Benedicto XVI, con motivo de la dedicación del templo de la Sagrada Familia. Diversos escenarios urbanos se adaptaron, con unos pocos elementos, para acoger el multitudinario evento. La plaza de la Catedral se convirtió en una gran estancia al aire libre, con el balcón del Palacio Episcopal como tribuna. Pero, sobre todo, las calles y plazas de los alrededores de la Sagrada Familia se ocuparon con sillas plegables y pantallas para seguir la ceremonia. Y ante la fachada del Nacimiento, se instaló un sencillo altar exterior para acoger uno de los episodios de la dedicación: el Ángelus. De hecho, Gaudí ya había diseñado este templo de tal manera que las imágenes religiosas que tradicionalmente se encuentran en el interior de una iglesia se trasladasen al exterior. Así, las cuatro fachadas se convierten en retablos que escenifican la vida de Cristo. Las calles adyacentes hacen las funciones de atrio de los gentiles y los ciudadanos pueden contemplar desde la calle los episodios del Evangelio.

La inteligente organización de la dedicación de la Sagrada Familia conllevó también el establecimiento de unos horarios. Mediante conos, vallas ligeras, banderolas, cintas o señales de tráfico trasladables, dirigentes y voluntarios cambiaron el uso de calles y plazas durante unas horas, para luego restablecer el tráfico y, con él, la actividad cotidiana. Si comparamos este episodio con algunos de los que se produjeron durante el Congreso Eucarístico de 1952, encontraremos notables similitudes estratégicas, a pesar de los más de sesenta años transcurridos (Fig. 10). ¿'No podrían ser buenos ejemplos para extrapolarlos a otras actividades del espacio urbano? (Fig. 11). De hecho, en muchas localidades de nuestro entorno ya existe una regulación horaria de las calles. Mercados semanales o ambulantes y espectáculos al aire libre cambian el aspecto y el uso de plazas y paseos de manera periódica o excepcional ${ }^{21}$. Una vez terminada la efemérides, la ciudad vuelve a su habitual estado de permanencia.

Estas muestras de practicidad, que aprovechan los enclaves y elementos urbanos disponibles haciendo partícipes así a todos los ciudadanos, constituyen excelentes ejemplos del uso potencial de la ciudad en general y de los espacios exteriores de las iglesias en parti- cular. No son tiempos para costosas construcciones ni grandes infraestructuras provisionales, inservibles para eventos futuros. Elementos flexibles y reversibles como toldos, sillas, vallas, cintas, conos, pintura para el tratamiento efímero del pavimento, o pantallas, unidos a una buena organización y gestión de los tiempos de ocupación del espacio urbano contiguo a las iglesias, son suficientes para acoger dignamente a un buen número de fieles. Una manera de operar más acorde con la austeridad presente en los Evangelios (Fig. 12).

\section{COROLARIO}

Louis I. Kahn afirma que «una ciudad se mide de acuerdo con el carácter de sus instituciones. La Calle es una de sus primeras instituciones». La Iglesia también lo es. Y añade: «Hoy, estas instituciones son objeto de discusión. Yo creo que eso ocurre porque han perdido las inspiraciones que habían motivado sus inicios»» ${ }^{22}$.

$\mathrm{Si}$, como afirma Kahn, Calle y Iglesia vuelven a ser instituciones sociales y cívicas, fieles a sus orígenes, ambas han de ser capaces de actuar coordinadamente, ofreciendo plataformas arquitectónicas para un uso comunitario. Y han de poder intercambiar funciones entre ellas de manera reversible, para que los límites físicos e ideológicos que han crecido entre la urbe y la ecclesia durante las últimas décadas ganen en porosidad y garanticen un mutuo enriquecimiento (Fig. 13).

\section{PROCEDENCIA DE LAS ILUSTRACIONES}

Fig. 01. AFB Arxiu Fotogràfic de Barcelona, 1982.

Fig. 02. Superior: Rafael Moneo Vallés, Rafael Moneo: 1967-2004 (Madrid: El Croquis, 2004). Inferior: Nick Ut. AP.

Fig. 03, 04, 08 y 11. Archivo de las autoras.

Fig. 05. Henk Hofstra.

Fig. 06. Izquierda: Museu Nacional d'Art de Catalunya. Derecha: AFB.

Fig. 07. ADB Archivo Diocesano de Barcelona.

Fig. 09. Joan Vilademunt.

Fig. 10. Izquierda: ADB Archivo Diocesano de Barcelona (Legajo 41: XXXV Congrés Eucarístic - Fotografies). Derecha: www.diariodemallorca.es.

Fig. 12. Archivo de las autoras, con la colaboración de Julio Álvarez Altadill.

Fig. 13. Izquierda: La Vanguardia.

\section{NOTAS}

(1) Sant Miquel del Port (Barceloneta), Sant Joan de Gràcia (Gràcia), Crist Rei (La Sagrera), Santa Maria del Remei (Les Corts), Sant Jeroni (Montbau), Sant Francesc Xavier (Can Peguera), Sant Mateu (La Guineueta), Sant Pius X (El Congrés) y 


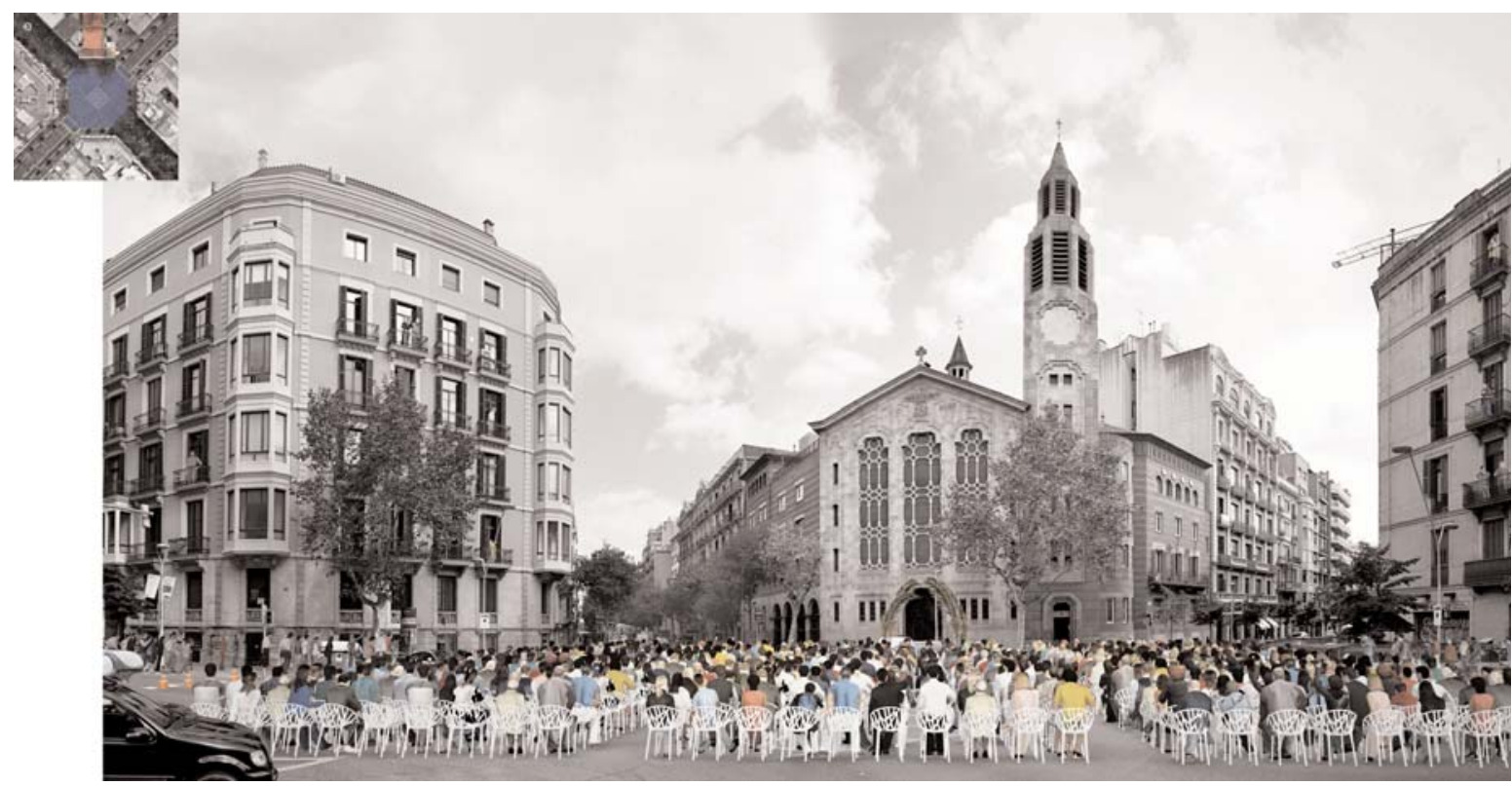

Fig. 12. Fotomontaje que muestra la posible conversión de la calzada de un chaflán del ensanche de Barcelona, frente a la parroquia de Mare de Déu dels Àngels. Con unos pocos elementos ligeros y trasladables, la buena gestión del tráfico y el establecimiento de unos horarios, este espacio exterior se convierte en la plaza de la iglesia.

Sant Ambrós (La Verneda) son nueve iglesias parroquiales de la ciudad de Barcelona que incluyen — desde el momento inicial de su proyecto - una gran plaza que las acompaña.

(2) De las 132 iglesias parroquiales que hay dentro de los límites municipales de Barcelona, 44 prestan su nombre —o el de su sacerdote fundador- al nomenclátor de la ciudad, bautizando plazas, calles, avenidas, ramblas e ¡incluso carreteras, barrios y montañas! Como ejemplos relevantes estarían: plaza de la Sagrada Família, carrer Sant Antoni Maria Claret, rambla de Santa Mònica, turó de La Trinitat y montaña del Tibidabo.

(3) Christopher Alexander afirma que estos espacios urbanos de paso y circulación —en oposición a los espacios urbanos para la permanencia- son centrífugos y no centrípetos. También Jan Gehl se refiere al espacio urbano como espacio social entre los edificios, subrayando esta capacidad de la calle de realizar funciones parecidas a las que se llevan a cabo en los interiores de las viviendas o edificios públicos. Cf. Christopher Alexander, et al., A Pattern Language - Un lenguaje de patrones: ciudades, edificios, construcciones (Barcelona: Gustavo Gili, 1980), 525-237. Jan Gehl, Life Between Buildings: Using Public Space (Copenhagen: The Danish Architectural Press, 2004 [1971]).

(4) Cf. Cerdà: las cinco bases de la teoría general de la urbanización (Madrid: Electa, 1996).

(5) «La calle es una estancia que expresa un pacto. En las ciudades actuales, las calles sin salida conservan aún su carácter de estancia. Las calles de cruce, después de la llegada del auto- móvil, han perdido por completo su calidad de estancia. Creo que el urbanismo puede empezar tomando conciencia de esta pérdida tratando de reintegrar la calle, donde la gente vive, aprende, compra y trabaja, a su papel de estancia comunitaria. La calle es una estancia comunitaria» (Christian Norberg-Schulz y Jan Georg Digerud, Louis I. Kahn, idea e imagen. Madrid: Xarait, 1981; 108-112).

(6) Alexander, A Pattern Language, patrón 106.

(7) Cf. George R. Collins, Christiane Crasemann Collins y Camillo Sitte, Camillo Sitte y el nacimiento del urbanismo moderno (Barcelona: Gustavo Gili, 1980). Aldo van Eyck, The child, the city and the artist (Amsterdam: Sun, 2008).

(8) Otro ejemplo lo tenemos en la transformación, también en color azul, de la calzada de la Gran Vía de Madrid, en mayo de 2010, que invitó a los ciudadanos a utilizarla como el césped de un parque.

(9) A finales de 1960, Rudofsky realiza un viaje por Europa para estudiar el espacio público en los países mediterráneos. A raíz de este viaje publica el libro Streets for People: A Primer for Americans (Garden City NY: Anchor Books, 1969). Véase pág. 15-21.

(10) La identificación de la calle con el teatro y viceversa, se corresponde con la idea italiana de que la calle es el supremo escenario. Sólo hace falta observar, entre otras, las perspectivas centrales de las ciudades ideales del Renacimiento, o los ejemplos del Teatro Olímpico de Vicenza, de Andrea Palladio, o del teatro de Sabbioneta, de Vincenzo Scamozzi. 

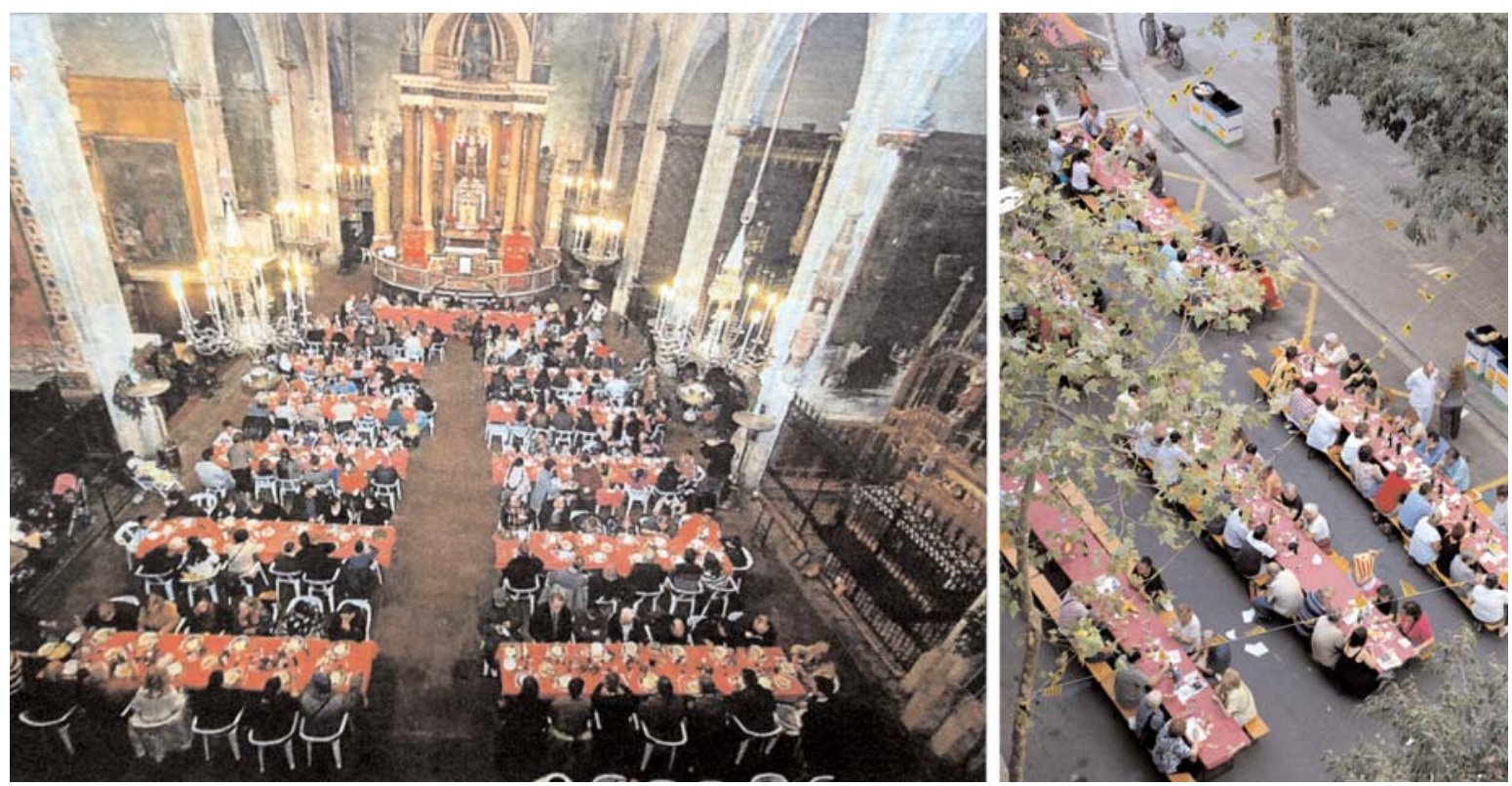

Fig. 13. Comparación de dos comidas populares en Barcelona, celebradas en lugares inusuales: el interior de una iglesia, el día de Navidad, y la calzada de una calle del ensanche, al final del verano. Las imágenes demuestran la capacidad de los dos espacios de acoger actividades idénticas, muy distintas a sus funciones habituales. Izq: Comida solidaria organizada por la comunidad de Sant'Egidio en la basílica de Sant Just i Pastor el 25 de diciembre de 2012. Der: Comida popular en una calle del ensanche el 11 de septiembre de 2010.

(11) La utilización de calles y plazas para todo tipo de actos públicos es un rasgo que caracteriza las ciudades mediterráneas desde épocas helénicas. Pero en especial durante el Barroco, calles y plazas adquieren un gran interés para montajes efímeros costosos y de gran efectismo, con la intención de demostrar el poder de aquellos que los hacen posibles. Las celebraciones religiosas se contaminan de esta espectacularidad que utiliza la ciudad como teatro para su particular representación de poder: festividades como San Juan, el Corpus Christi o la Semana Santa se revisten de pompa y ornamento, acentuando el espectáculo pero, a la vez, olvidando el aspecto más intrínsecamente religioso del ceremonial. Los cronistas de la época describen el levantamiento de costosos altares callejeros para asombrar a las gentes: hasta catorce altares ricos y profusamente adornados describe León Pinelo en sus Anales de Madrid, sin nombrar en ningún momento la vertiente espiritual del evento (cf. José Antonio Maravall Casesnoves, La cultura del Barroco. Barcelona: Seix y Barral, 1975; 453-498).

(12) El puente de unión entre las dos torres romanas de la puerta decumana, junto a la catedral, por ejemplo, se convierte en más de una ocasión en un altar al aire libre para la celebración de misas populares (cf. Josep Maria Garrut i Romà, 600 anys de plaça Nova. Barcelona: Selecta, 1955; 37-39).

(13) Rudofsky, Streets for People, 15-21.

(14) Cf. Tom Avermaete y Joan Ockman, Another Modern: The Post-War Architecture and Urbanism of Candilis-JosicWoods (Rotterdam: NAi, 2005), 94.
(15) El Congreso Diocesano de Acción Católica (1949), la Semana Sacerdotal (1950), la Santa Misión (1951) y, el más importante, el XXXV Congreso Eucarístico Internacional (1952) (cf. Francesc Muñoz Alarcón et al., Gregorio Modrego Casaus. Obispo del XXXV Congreso Eucarístico Internacional de Barcelona. Barcelona: Arzobispado de Barcelona, 2002).

(16) La ceremonia más importante del encuentro católico tiene lugar en la avenida Diagonal y congrega a más de doscientos cincuenta obispos de todo el mundo, quince mil sacerdotes y dos millones de fieles (cf. Muñoz, Gregorio Modrego).

(17) Entre otros ejemplos, grandes sectores de la Ciudad Condal se urbanizan durante las exposiciones universales de 1888 y 1929.

(18) Además del campeonato de vóley disputado en la explanada del cambio de guardia de la caballería del Downing Street, el lago Serpentine del Hyde Park acogió las pruebas de natación de larga distancia y las calles del centro actuaron como pistas para las carreras de ciclismo a contrarreloj y para la maratón.

(19) Cf. Richard Sennett y Marco Aurelio Galmarini, El Artesano (Barcelona: Anagrama, 2009), 245-252.

(20) Uno de los ejemplos lo encontramos en el distrito de Cutupú, en el municipio de La Vega, Rep. Dominicana (2012).

(21) El festival Grec (la suma de espectáculos veraniegos que organiza el Ayuntamiento de Barcelona) ya hace uso de algunos espacios públicos al aire libre, muy significativos para la ciudad.

(22) Norberg-Schulz, Louis I. Kahn, 110. 